\title{
Implementing Active and Collaborative Techniques: Lectures, Labs, Grading and More
}

\author{
Kenneth J. Reid, \\ Indiana University Purdue University Indianapolis (IUPUI)
}

\begin{abstract}
:
There are many papers on the benefits of introducing active and collaborative learning into the classroom. These benefits include those of increased involvement of students in the learning process to lectures that are perceived as more exciting. Many workshops are available at conferences such as the American Society of Engineering Educators Annual Conference and Frontiers in Education; many classes and workshops are presented in conjunction with these conferences as well as stand-alone activities. Some may even be available on campus for instructors.
\end{abstract}

This paper will discuss practical applications of active and collaborative teaching techniques which can be used in the classroom with little to moderate preparation. In addition, the paper will describe various activities the author has collected which can be used to increase lecture and lab involvement in the lecture and laboratory material without costing excessive classroom time. The paper should be especially of interest to new educators and instructors looking for ways to begin introducing interesting and useful techniques into their lectures. This will not be an exhaustive list of techniques, but rather, a discussion of techniques which can be practically implemented.

\section{Introduction:}

Through attendance at different teaching workshops, seminars, and trial and error, many instructors accumulate good ideas on more effective teaching. Some of these ideas are lost during the semester as research, service, publishing, and teaching preparation consume all available time. However, some ideas can be implemented fairly easily, and have had excellent results for a minimum investment of effort and time. This paper is designed to discuss some ideas which have been successfully implemented in order to inspire others to try to spice up an otherwise dry lecture. The main reason for such a paper can be seen in the goal statement of a recent seminar:

"The Academy of Instructional Excellence (Master Teacher program) is built on the principle that teachers teach other teachers. Loosely translated: teachers steal other teachers' ideas." 1,2

Most of the ideas I have tried have been stolen from, or rather, have been learned from other

"Proceedings of the 2002 American Society for Engineering Education Annual Conference \& Exposition Copyright ( 2002, American Society for Engineering Education" 
professors. In fact, at the conclusion of a follow up meeting to this seminar, one participant said "These ideas are great - and I'm not creative enough to come up with all of this on my own."

The following suggestions have worked in practice before and required little to moderate preparation for the benefits. ${ }^{3}$

\section{Lecture Techniques:}

Live demonstrations:

A typical lecture discussing a 7-segment display and driver (an electronic design similar to one digit on a digital clock) can involve a chalk drawing and a description of the hardware. The instructor would probably mention that resistors must be used between these components to avoid destroying the LEDs. The student would more likely remember the point if the instructor wired a simple demo, powered the display up, and the students saw the LEDs light brightly and then go out. A visual demonstration can stress a point that a student may miss in the middle of a typical lecture, and should help a more visual learner. Many of these techniques like this will also serve to break the lecture into smaller, more manageable segments which both the instructor and students will appreciate.

\section{Group (spontaneous) quizzes:}

I have found that nothing can break up a dry lecture and revive the students like a spontaneous quiz. However, because there is never enough lecture time to cover everything, the quiz should be an alternative method to cover an upcoming example. In other words, have the students work on the next problem instead of working it through on the board. In order to avoid stress associated with a pop-quiz, I have the students turn and form groups of four or five students, have them quickly designate someone who will record the answer, put all names on the paper, and open the floor for discussion among the groups. Groups may ask questions of me or other nearby groups. Rather than stopping the work at a certain time, I will typically wait a few minutes then, while the groups are still working, I'll begin to write the correct solution on the board. Groups who are progressing well can continue and check their answer at the end, while groups that are stuck resort to what they would have done in the first place: getting the solution from the board. The quizzes may be turned in or left with the students. If turned in, I choose to give all participants full credit for the quiz rather than grading their answer, since the answer was available before they were turned in. This also serves as an incentive to attend class.

One of the most important advantages in this technique include reviving the interest of the students by breaking the lecture with an activity - in other words, waking up the students - with little or no preparation beforehand. This technique can be used as needed. Another advantage is that it takes just a bit more lecture time than demonstrating a problem on the board in the typical fashion. Finally, it tends to generate more insightful questions from the students since they were involved in the solution rather than just watching someone else who was involved. ${ }^{4,5}$

\footnotetext{
"Proceedings of the 2002 American Society for Engineering Education Annual Conference \& Exposition
} Copyright @ 2002, American Society for Engineering Education" 
Think - pair - share:

Think-pair-share is an easy to use technique which can quickly gain the students' attention and get them involved in the topic at hand. Students are paired with someone: one suggestion is to pair them with someone outside of normal study groups. The instructor poses a question for the class to answer. Students are given 30 seconds to two minutes to "think" of an answer on their own. They are then to turn to their partner, and the "pair" discusses their individual answers and formulates one group answer. The instructor then calls on or asks for volunteers to "share" their answer. This technique will get the attention of the students, and they tend to be more willing to share their group answer; if it is incorrect, they feel less isolated and embarrassed. Also, this technique offers a quick break in the class while maintaining the flow of information. ${ }^{6,7}$

\section{Laboratory Techniques:}

Practice lab practical exam:

Many laboratory classes have a lab practical exam, where a student goes to their lab and receives a typical assignment; they are then responsible to design, simulate and/or build to demonstrate their proficiency in the laboratory. I have used this in all of my lower level laboratories, while upper level courses will have larger multi-week projects demonstrating their performance in the laboratory. I have found that, regardless of how many times the class is warned that the lab practical is soon and they should work on their lab skills, I will have students that fail mainly due to lack of practice. I have addressed this with a "practice lab practical" about three weeks prior to the real exam. This will require some preparation and about an hour of laboratory time, although the practice practical can be a laboratory activity they would normally do during the laboratory period. Using one of the assigned tasks for that laboratory period, require that students work on their own and receive a grade for one specific problem, allowing only a certain amount of time. The grade for this portion does not need to be overly significant, but it can serve to convince a somewhat reluctant student that the lab practical exam should be taken seriously.

\section{Optional help lab session:}

This will require a significant time investment on the part of the instructor, but can really benefit students. I plan a session around the second week of the semester for students who may be weak in some area of lab. Since we do not typically have classes on Fridays, one of these sessions can be scheduled for a Friday. This lab session is entirely optional, although some students are strongly encouraged to attend. I will usually have some basic laboratory exercises ready, and have students work through these essentially with the instructor as the lab partner. This can serve as a confidence booster for a student, hopefully helping the student increase their laboratory involvement through the rest of the semester.

Our department holds Saturday open labs through most of the semester. The labs are open and an instructor is available on Saturday mornings until noon. As long as the whole department pitches

\footnotetext{
"Proceedings of the 2002 American Society for Engineering Education Annual Conference \& Exposition
} Copyright (C) 2002, American Society for Engineering Education" 
in, each instructor should only have to work one or two Saturday mornings. The students really seem to appreciate this extra time; especially toward the end of the semester.

\section{Grading Techniques:}

\section{Rubrics:}

Grading rubrics serve at least two purposes: to give the student meaningful feedback and to help insure more consistent grading on assignments for which grading may prove to be subjective. Anyone who has graded 30 written papers on the same subject knows that the papers will vary greatly in quality, and some will be "average". However, feedback to the student consisting of a few red marks through the assignment with a " $\mathrm{C}$ " at the end will not help the student improve. A simple rubric can be developed quickly, or a more elaborate rubric may be found (and modified if necessary) from a colleague or the Internet.

One example of a simple rubric is shown in Table 1. Space is available to make notes to the

\begin{tabular}{|c|c|}
\hline Writing: & \\
\hline spelling / grammar (10) & \\
\hline followed Web guidelines / formatting (10) & \\
\hline $\begin{array}{l}\text { Tech content: (10) } \\
\text { (accurate data, descriptions, calcs) }\end{array}$ & \\
\hline $\begin{array}{l}\text { Presentation of design: (10) } \\
\text { Participation (Peer evaluation turned in) (10) }\end{array}$ & \\
\hline
\end{tabular}

student, and these comments are more likely to be read by the student who may not flip through a report looking for comments written in the margins.

Other rubrics can be more detailed, and can be modified to meet the grading requirements of almost any assignment. ${ }^{8}$

Grade strips:

This technique gives the students feedback at regular intervals. Although there are some options which will post current grades over the Internet, such as establishing a login procedure or implementing some course design Internet ${ }^{9}$ packages, these are sometimes impractical. I have a page on my grading spreadsheet which has larger than normal rows with larger text, which displays each grade on each assignment, as well as the current weighted average in the class. When I return an exam, I literally cut and paste (actually cut and tape) a strip of paper (Figure 1) showing each grade and the current average in the class inside of each exam. This lets students know how they are doing, if they have missed homework or laboratory assignments, and how

"Proceedings of the 2002 American Society for Engineering Education Annual Conference \& Exposition Copyright ( 2002, American Society for Engineering Education" 
close they are to the next higher or lower grade.

\section{Techniques for Homework and Other Assignments:}

Figure 2: Grade strip, showing all grades for the semester and current average

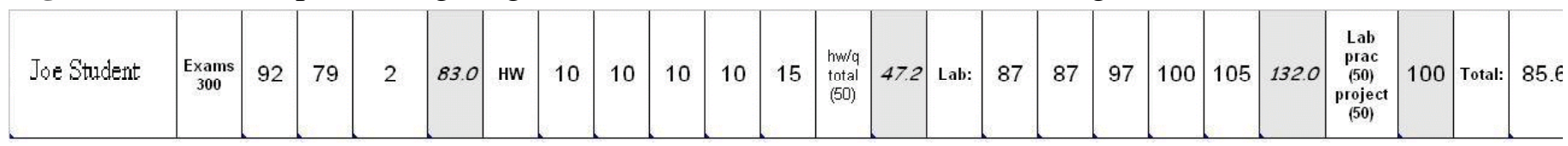

Group homework assignments:

Our campus is a commuter campus, so requiring homework to be done in groups is not practical. I do strongly suggest that homework should be done in a group, and explain that this does not mean one does the work while another copies. However, since I have found that students crave extra credit, I offered extra credit homework, consisting of three parts. First, all students who are interested stay after class for five minutes, where groups of four or five are formed. These groups must work on the regular assignment together. Whoever works in the group and turns in the assignment is allowed to work additional problems, again with a group, for extra credit. The extra problems are to be turned in along with a very brief peer and self evaluation discussing who was present the whole time, who pulled their share and who perhaps did not. Students completing this assignment receive credit equal to one homework assignment. This is one way students who need extra credit can meet other students and hopefully begin to study with their classmates in a group. The only additional preparation required was to develop an additional homework assignment for a fraction of the class. ${ }^{10}$

\section{Exams / Final Exams:}

\section{Group exams:}

This suggestion should be reserved for very special cases, but it was used in two instances I am aware of, and was very successful in both cases. Both courses were upper level courses, so most of the students were responsible and it was a safe assumption that all students had studied for the final exam. In both of these cases, the instructors knew the students very well, and had exceptionally successful semesters. The students in both classes had worked on a few major assignments and projects in groups, and all of the groups showed a desire to excel in their work. Another similarity was that the students did not know that part of their final exam would be based on an in-class group final exam until they arrived in the classroom for the final - this was necessary to guarantee that everyone would study and prepare for the final. Finally, both classes had a final exam consisting of a take-home portion and an in-class portion.

In one of the examples, students had a take-home portion of the final exam worth 100 out of 150

\footnotetext{
"Proceedings of the 2002 American Society for Engineering Education Annual Conference \& Exposition Copyright (C 2002, American Society for Engineering Education"
} 
points, with the other 50 in an in-class cumulative exam. When they arrived, they were told to split into three groups of six students each. Any student who felt that this could have a detrimental effect on their grade was given the option to take the exam as is typically done; no students opted for this. The groups were formed based on a consistent and successful grouping scheme, allowing each group to consist of students who had worked together on major assignments. Each group appointed an official writer, and was allowed a reasonable amount of time per problem for discussion within the group. The scores were a 49, 47.3 and 44.6 out of 50, and each participant received the group score. This meant that the bulk of the score on the final exam was due to the take-home portion. One student, after leaving the final exam and walking away from the classroom was overheard to say "Everything I learned this semester makes sense after these two hours!"

I would not recommend this technique for any lower level courses or for a particularly immature class. Also, it would be particularly risky to announce this group exam in advance, as there would probably be a number of students happy to let a group score carry them, and would gladly refrain from studying.

\section{Techniques for "Major" Projects:}

Major projects are usually multi-week projects requiring steady progress and a written and/or oral report at the conclusion of the project. Implementing a major project into the curriculum does require preparation and development, but this can be one of the most valuable tools for a student, since this type of project should most closely match a project they will see in industry. Although it is difficult to jump into a major project with little preparation, some possibilities and suggestions include:

Short research topics:

Instead of a one class lecture on a topic, adjourn the class to a nearby computer room and assign the topic as a research topic, allowing students to investigate the topic during the class period and prepare a brief report as homework. This may be particularly useful for an introduction to a major topic: one example used was the differences between the architecture of Complex Programmable Logic Devices (CPLDs) and Field Programmable Gate Arrays (FPGAs). Students investigated the basic architecture, and in case students did not grasp the differences, they were made apparent in subsequent lectures and laboratory experiments.

Oral presentation evaluation:

One of the courses in the curriculum, Electronics Manufacturing, has a number of challenging projects, including specifying a manufacturing line for a fictional company within supplied guidelines. As usual for project of this scope, the groups are to prepare a presentation with their results, and these are usually presented to the instructor. One twist we have used is to invite a number of industry "experts" to form the review panel for our fictional company. These include

"Proceedings of the 2002 American Society for Engineering Education Annual Conference \& Exposition Copyright $@$ C 2002, American Society for Engineering Education" 
manufacturing engineers, sales representatives, Vice Presidents, and owners of local manufacturing firms. The importance of this presentation is stressed, and students are told that they will not just present in front of the class. We have the students travel to a nearby plant where the groups who are not currently presenting are involved in a laboratory until they are called to present. Although told that they would not simply present to the class, they have typically been quite surprised to see a panel of people to present to, and are often surprised to be asked questions as through they were in industry. This "panel of experts" will ask questions of the group until they have to admit that they don't know an answer. This has been extremely successful for the industry representatives as well as the students.

Of course, there does need to be some preparation to assemble a suitable panel, but the rewards are many. The students have the "opportunity" to experience presenting to a potentially hostile audience before they are employed, a fact that is explained in the next class period. Industry representatives are able to see that the students can do excellent work on a major project, and have made some contacts with students about future employment. Incidentally, one of the firms who participates regularly is setting up a scholarship for an outstanding electronics manufacturing student in the near future. ${ }^{11}$

\section{Instructional Feedback:}

Most institutions will survey students at the end of the semester to evaluate each class. However, this feedback usually doesn't reach the instructor until well into the next semester. Feedback during the semester can be much more useful.

\section{$3 \times 5$ cards:}

This is one of the easiest methods to receive feedback, and should only require one or two minutes at the end of a lecture. Distribute $3 \times 5$ cards or other paper to each student and ask for feedback. There are a number of suggestions the instructor can suggest for specific feedback, including asking for topics that seem to be going very well, seem to be muddy or slightly confusing, seem to be very difficult; any question generally receives a significant amount of response.

One-minute paper:

This is a very similar idea to the previous suggestion, but the students are free to write anything about the course in one or two minutes. For a variation, allow a few more minutes and have the students join into pairs, compare and combine their comments - another application of think-pair-share.

\section{Conclusion:}

This paper discusses some ideas which can be implemented into a classroom with little to

"Proceedings of the 2002 American Society for Engineering Education Annual Conference \& Exposition Copyright ( 2002, American Society for Engineering Education" 
moderate preparation. Instructors who are interested in improving their teaching, especially if their teaching has perhaps fallen into a routine of "chalk and talk", may be able to try one or more of these methods and inspire, or at least awaken the student. Once the instructor is inspired to improve teaching, there are many opportunities to study techniques at conferences or seminars, and these should be investigated. In other words, spend an extra day or perhaps one evening attending a session or workshop on improving teaching. Be sure to take the next step and actually try one or more new ideas - your students will appreciate it, and maybe find the inspiration they need to succeed!

1. URL for the Virginia Master Teacher Seminar, similar to the Indiana Master Teacher Seminar: http://www.sv.vccs.edu/mteacher/MAIN.HTM

2. Hogan, Jean E. "Attending the 1996 Virginia Master Teachers Seminar", Inquiry, Volume 1, Number 2, Fall 1997, 61-63

3. Reid, K.J., "More Effective Teaching: One Year After the National Effective Teaching Institute", Proceedings of Frontiers in Education Conference, Session 12d7, 1999

4. Smith, K.A., "Cooperative Learning", Proceedings of the1998 American Society for Engineering Education National Conference, Session 2230, 1998.

5. Dyrud, M.A., "Getting a Grip on Groups", Proceedings of the1999 American Society for Engineering Education National Conference, Session 3230, 1999.

6. URL: http://www.wcer.wisc.edu/nise/CL1/CL/doingcl/thinkps.htm

7. URL: http://home.att.net/ clnetwork/thinkps.htm

8. Thomas A. Angelo and K. Patricia Cross, "Classroom Assessment Techniques", San Fransisco, Jossey-Bass Publishers, 1993.

9. Christe, Barbara, "Web-Based Courses: What Students Need to Know Aside from Content", Proceedings of the 2001 American Society for Engineering Education National Conference, Session 1347, 2001.

10. Reid, K.J., "Measuring Improvement Due to the Implementation of Active and Collaborative Teaching Techniques", Proceedings of the 2001 American Society for Engineering Education National Conference, Session 2230, 2001.

11. Green, Colonel Robert L., "Improving Listening, Teamwork and Leadership Skills Through Innovative Civil Engineering Classroom Experiences", Proceedings of the 1999 American Society for Engineering Education National Conference, Session 1615, 1999.

\section{KENNETH J. REID}

"Proceedings of the 2002 American Society for Engineering Education Annual Conference \& Exposition Copyright @ 2002, American Society for Engineering Education" 
Kenneth Reid is an Assistant Professor in Electrical Engineering. He has a BS degree in Computer and Electrical Engineering from Purdue University, and an MSEE from Rose-Hulman Institute of Technology. He is currently working to implement advanced digital design techniques into early digital courses, electronics manufacturing, and implementing different learning and teaching styles in the classroom. 